the Electron" appeared in the Proceedings in 1928. In the same decade, the Biological Reviews were first published, and this has since become one of the society's most important enterprises.

Among Cambridge people, the Philosophical Library is probably the best known contribution to the life of the university-its provision of periodicals for all members of the university, as well as Fellows of the society, has filled a valuable service throughout its existence, and since 1967 it has been known as the Scientific Periodicals Library. It now obtains about 1,100 journals in exchange for its own publications.

Celebrations of what the society is calling its sesquicentenary are to include the presentation of honorary degrees by the university, a series of special lectures and a dinner in St Catherine's College on November 3. Some time during the festivities, new plans will be announced to expand the activities of the society. With a financial situation that is better than ever before and the continuation of widely respected meetings and publications, the next 150 years are likely to be as fruitful as the last.

\section{RESEARCH PLANNING What is it Worth?}

THE fourth of the science policy studies produced under the aegis of the Council for Scientific Policy is the most obscure yet. The subject is An Attempt to Quantify the Economic Benefits of Scientific Research (HMSO, 4s). Professor Harry Johnson of the London School of Economies, the member of the council who has superintended the study, acknowledges in his introduction that "it is by no means the case that the sole justification for fundamental research is utilitarian". What the authors of the study, Mr I. C. R. Byatt and $\operatorname{Dr} \mathrm{A}$. V. Cohen, have done is to suggest a number of studies which could bo made of the ways in which the economic success of what are called "science-based industries" might be traced back to certain discoveries in fundamental science. According to Professor Johrson, the notion that a part of this "ambitious" plan should be undertaken has been accepted by the Council for Scientific Policy, although there is as yet no news of the industries likely first of all to be favoured by the study.

The study starts with a long and somewhat wooden list of the potential benefits of what the authors call "curiosity-oriented research". Trained manpower is at one end of the scale, and culture at the other, but the study is mainly concerned to quantify the possible value of delayed industrial applications of scientific research, "the absorption into the infrastructure of science, and the subsequent industrial application, of a whole host of apparently minor discoveries", the awareness of developments in other countries which research programmes can provide and the way in which scientific research equips people to "look for the possible commercial developments of scientific discoveries". In passing, however, the study does trample on the feelings of those who argue that science is culturally important-the authors say that because the British government spends only $£ 24$ million a year on the support of the Arts, it would be "difficult to justify" the spending of more than $£ 5$ million a year on the cultural objectives of science "in view" of the smaller number of people able to enjoy science as a cultural activity". Whether it will be possible to throw more light on this problem by comparing the audiences for broadcasts of musical concerts and science programmes, as the study somewhat wistfully suggests, is another matter.

The chief preoccupation of the study is to put a numerical value on the benefits of research to industry in general and individual industries in particular. Quite properly, it works entirely in terms of costs and cash benefits discounted to some standard date. The argument is that the value of the scientific discoveries underlying a particular industry can be measured by the difference between the discounted sum of world sales in the industry and the discounted sum of all the associated costs-running costs, capital investment, market research and applied research. The object of the formalism is to make it possible to write down the partial differential coefficients by means of which are calculated the marginal changes brought about by variations of the level of expenditure on scientific rescarch, but the usefulness of the procedure is to a very large extent undermined by casual references such as that to the need for including social costs and benefits-thin ice for most people. If it is also reckoned that a properly discounted estimate of the value of scientific research is likely often to be the difference between two very large numbers, it seems most probable that the Council for Scientific Policy will have to sponsor a great many of the retrospective studies specificd in outline before the Treasury would allow it to use the generalizations which emerged as argument in an annual scramble for the research budget.

\section{ENGINEERING \\ Cooperation in Electronics}

THE annual report of the Institution of Electronic and Radio Engineers (Proc. IERE, October 1969) reflects the growing cooperation between institutions and other organizations concerned to make the best use of British potential in electronic engineering.

One of the main problems is establishing common qualifications for different grades of engineer, and the Council for Engineering Institutions has succeeded in doing this for professional engineers. From next year individual institutions will stop setting their own examinations and all chartered engineers will be registered by the Council for Engineering Institutions.

The next step is to establish a register for other grades of engineers-possibly technician engineers and engincering technicians - and the CEI has a working party looking into this now.

In line with its policy of wide-ranging cooperation the IERE has joined with the Institute of Physics and the Physical Society, the Institute of Mathematics and its Applications, and the Institution of Electrical Engineers in forming a Standing Committee of Kindred Societies. Its chief function seems to be to organize common meetings and conferences and to focus attention on borderline subjects. The IERE and the IEE have been closely cooperating for some years in ficlds such as medical and biological engineering, computers and a project to develop a British information retrieval system. Both institutions have, however, decided firmly in favour of remaining separate organizations.

In research and development, the National Electronies Council is responsible for ensuring efficient 
communication between the government, the universities and the electronics industries. But in his inaugural speech last week, the new president of the IERE, Mr Harvey Schwarz, said he thought the NEC should a]so advise on education, manpower and exports. $\mathrm{Mr}$ Schwarz, the managing director of Decca Navigator Co., Ltd, and a director of Decca Ltd and Decca Records Ltd, also spoke in favour of private enterprise for stimulating developments in electronics and against large scale mergers which he called "gadarene swinemanship".

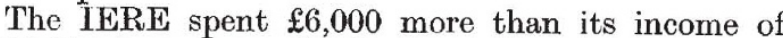
$£ 130,000$ last year, chiefly because of increased expenditure on computer services, postage and telephone and the institution publications. This may mean increases in the fees for conferences, the price of the journals and perhaps subscriptions next year.

\section{WILD LIFE}

\section{Dead Birds and Hot Air}

A REPORT that some of the dead seabirds from the Irish Sea contained "possibly significant" quantities of polychlorinated biphenyls was one of the few positive results to emerge from a meeting to discuss progress in in. vestigating the 10,000 deaths held at the Natural Environment Research Council in London on October 24. No single cause, however, will yet account for the situation. Much of the meeting's value lay in stopping paths of speculation-apparent false alarms of dead seals or effects on fish and plankton-and emphasizing instead the continuing search for infection or pollution.

The evidence for the biphenyls, which are industrial wastes, came from the Nature Conservancy's Monks Wood Exprrimental Station. One of the difficulties in assessing whether the materials may be involved is the lack of information about their distribution and toxicity, but it so happens that Monks Wood conducts routine monitorings of concentrations in guillemot eggs from the Irish Sea area. These measurements provided a background against which the amounts (of the order of hundreds of parts per million) in dead guillemots have stood out sharply, and so have justified the ascription of significance.

There is, however, controversy over the question of just what is signified. It is clearly not possible to draw general conclusions, because only nine birds have been analysed. The issue is whether the concentration that has been found could be regarded as toxic. One investigator thinks that biphenyls may be merely a fashion-a new compound has turned up, so everybody is making a fuss, although, given sufficiently sensitive measurements, practically any industrial compound. could be found. Certainly no direct link has been identified between biphenyls and the present deaths, but, on the other hand, there is evidence from elsewhere that may point at least towards a correlation.

This concerns measurements reported in Nature (224, 247 ; 1969) of biphenyls in white tailed eagles from the Baltic. The population of this species is falling, the birds analysed were dead and the biphenyl concentration was of the same order as that in the samples from the Irish Sea. What is not clear, however, is the relationship between toxic concentrations for eagles and guillemots, and there are still no grounds for antipollutionists to proclaim a new scapegoat.
In the United States the Monsanto Company, which manufactures products containing $\mathrm{PCBs}$, has investigated their toxic effect on rats, and during 90 day studies a concentration of 100 parts per million apparently gave no adverse results. This, of course, need imply nothing about what happened to guillemots with a similar dose. Present work at Monks Wood on the toxicology of these compounds to birds may give some of the answers. The pathologists, however, have yet to come up with details of possible infections among the birds, and the London meeting also pointed to the likely role of severe gales coinciding with the auks' moulting period, so that PCBs may turn out to be another dead end.

The lack of organization surrounding the whole affair, reflected in the slowness of getting results (first reports of deaths were in mid-September), does raise the question of whether there should have been some kind of emergency service to coordinate investigations, which have been mainly voluntary. For example, should NERC itself employ someone to be responsible for linking suitable establishments to look into any large-scale natural disaster as soon as the first evidence appears? This time, much of the initiative originated with the Royal Socicty for the Protection of Birds, and only after work was well under way of its own accord were the participants officially brought together.

\section{ELECTRICITY \\ Responding to Change}

from our Special Correspondent

Capenhurst, Cheshire, October 24

THE sagging fortunes of the electric-arc furnace should revive if the trials being mounted by the Electricity Council and the British Steel Corporation with pre-reduced iron bear out their initial promise. The critical shortage of scrap steel which is jeopardizing the industrial future of the electric-are furnace has led to a determined effort to find an alternative charge, and pre-reduced iron, produced by concentrating iron ore and heating it in the presence of a reducing agent, seems to be a promising alternative. It can be produced cheaply as pellets or briquettes and then can be fed continuously to the furnace once the required temperature has been reached. Adjustments to the quality of the steel can be made during the feed, thereby eliminating the refining process. Plant trials with both pellets and briquettes are said to have been encouraging, and the Electricity Council and the BSC are now studying the economics of a complete furnace system.

A new high capacity storage heater has also been developed at the Electricity Council's research laboratories here. It is based on a two layer concept first demonstrated two years ago and consists of an inner core of feolite, a sintered iron ore with a thermal capacity near that of cast iron, and an outer layer of barytes, which is a good insulator with a high thermal capacity. The idea is that the heat will be delayed by the barytes, so that the storage heater will radiate over a longer period. The Electricity Council claims that the system is thirty per cent more efficient than storage heaters now in use and that it should be capable of releasing heat even during the long English afternoon. The first batch of 350 feolite-barytes heaters is now being produced and should be available to the public within the next two years. 